\title{
Experimental study of the mechanical behavior of self-compacting concrete based on fracture mechanics
}

\section{Estudo experimental do comportamento mecânico do concreto autoadensável com base na mecânica da fratura}
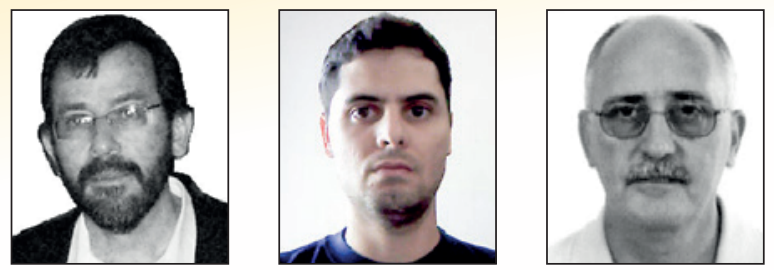

G. O. RIBEIRO

gabriel@dees.ufmg.br

P. C. GUETTI b guettipc@gmail.com

P. SERNA ${ }^{\circ}$ pserna@cts.upv.es

\begin{abstract}
Considering the physical nonlinearity of concrete and the fundamentals of fracture mechanics for quasi-brittle materials, the objective of this study was to determine the fracture energy and the length of the fracture process zone (FPZ) as well as the modulus of elasticity, the tensile strength and the compressive strength of self-compacting concrete (SCC) to characterize its mechanical behavior. A series of tests, including a three-point bending test of SCC and conventional vibrated concrete (CVC) specimens, with a notch at mid-span, and tensile and compressive tests were performed. The mechanical parameters obtained from the CVC specimens were considered as a comparative reference. The effect of the following variables was evaluated and considered at two levels: compressive strength ( 30 and $50 \mathrm{MPa}$ ), granular composition (fine and coarse particle size) and maximum diameter of the aggregate $(12$ and $20 \mathrm{~mm}$ ). The effect of these variables on the mechanical behaviors of the SCC specimens was evaluated based on the test results of specimens of four types of concrete, which were obtained from the combination of the variables. The bending tests were performed according to the RILEM TC 89-FMT recommendations, which are based on the size-effect method.
\end{abstract}

Keywords: fracture mechanics, self-compacting concrete, size effect.

\section{Resumo}

O objetivo principal deste trabalho é caracterizar o comportamento mecânico dos concretos autoadensáveis (CAA), tendo em vista a não linearidade física e os fundamentos da mecânica da fratura para materiais parcialmente frágeis. Neste trabalho busca-se a determinação da energia de fratura e do comprimento da Zona de Processo de Fratura, além do módulo de elasticidade, da resistência à tração e à compressão. Para tanto, foi realizada uma série de testes constando vigas de CAA submetidas à flexão de três pontos e vigas de concretos convencionais vibrados (CCV), com entalhe no meio do vão, sendo que os parâmetros dos corpos-de-prova de CCV serviram como referência comparativa. Foram considerados com dois níveis de resistência à compressão (30 e $50 \mathrm{MPa}$ ), duas composições granulométrica (granulometria fina e granulometria grossa) e dois diâmetros máximo do agregado (12 e $20 \mathrm{~mm}$ ). A avaliação da influência destas variáveis no comportamento mecânico do CAA foi feita a partir da dosagem de quatro tipos de concretos obtidos pela combinação das variáveis mencionadas. Os ensaios de flexão foram feitos de acordo com a recomendação do RILEM TC 89-FMT, que se baseia no Método do Efeito de Tamanho.

Palavras-chave: mecânica da fratura, concreto autoadensável, efeito de tamanho. 


\section{Introduction}

Self-compacting concrete (SCC) originated in Japan in 1986; the first use of SCC occurred in 1988. SCC can be defined as a concrete that can flow and spread in a mold by the action of its weight and can transpose obstacles without exhibiting segregation and exudation, which ensures a uniform aggregate distribution throughout the volume of the structure. These features are the main characteristics of this composite in its fresh state.

SCC is a typical case of quasi-brittle material, which exhibits a softening branch in a stress-strain diagram after attaining the maximum load value in a tensile test, in which the load value continuously decreases with a significant increase in deformation. The behavior of concrete can be described based on fracture mechanics for a more realistic simulation of mechanical behavior. The proper use of fracture mechanics via the application of mathematical models is more representative of the actual behavior of concrete and can aid in the formulation of more accurate constitutive models that are less subject to scale effects. For the application of fracture mechanics, the determination of experimental parameters that characterize the fracture process is required. The integration of mathematical models and the ability to experimentally determine the parameters of these models enables the use of concrete fracture mechanics in practical applications (BITTENCOURT [1]).

BAŽANT [2, 3] argues that the size effect observed in concrete structures is one of the main reasons for the application of fracture mechanics concepts in the analysis of concrete structures. The easiest way to apply these concepts is to use formulations of linear elastic fracture mechanics (LEFM). Based on the effective crack model and its dependence on the size of a structural element, BAŽANT et al. [4] defined the fracture energy $\left(G_{f}\right)$ and the length of the fracture process zone (FPZ) $\left(c_{f}\right)$ for infinite-size structures of any geometry. To experimentally determine $G_{f}$ and $c_{f}$ from specimens of moderate size, the authors proposed the size effect law to characterize the material and to isolate the influence of the size and geometry of a structure.

The determination of the fracture energy and length of the FPZ are the main objectives of this study. The modulus of elasticity and the tensile and compression strengths were also investigated. Numerous SCC beams (with a notch at mid-span) were subjected to a three-point bending test. Simultaneous tests were performed with an analogous series of conventional vibrated concrete (CVC) beams with a notch at mid-span. The parameters of the CVC specimens served as a comparative reference. Concrete with two levels of compressive strength (30 and $50 \mathrm{MPa}$ ), two granular compositions (fine and coarse particle sizes) and two maximum aggregate diameters (12 and $20 \mathrm{~mm}$ ) were investigated. The influence of these variables on the mechanical behavior of SCC was evaluated by mixing four types of concrete that were obtained by combining the variables of interest. The three-point bending tests were performed according to the RILEM TC 89-FMT recommendation, which is based on the size effect method.

\section{Materials and concrete compositions}

The materials used to produce the various types of SCC in this experimental program included the following cements: CEM I 52.5R (UNE-EN 197-1, 2011), rated as high-strength Portland cement according to European standards, and CEM II/BM (V-LL) $32.5 \mathrm{~N}$ (UNE-EN 197-1, 2011), with the addition of silica and limestone

\section{Table 1}

Composition of the cements

\begin{tabular}{|c|c|c|}
\hline \multicolumn{2}{|c|}{ Cement } & CEM I 52.5R \\
\hline Components & CEM II/B-M(V-LL) & $-100 \%$ \\
\hline Clinker & $65-79 \%$ & $0-5 \%$ \\
\hline Silica and limestone fly ash & $21-35 \%$ & - \\
\hline Minor constituents & $0-5 \%$ & $3.4 \%$ \\
\hline Chemical characteristics & - & - \\
\hline Sulfates & $<3.5 \%$ & $1.7 \%$ \\
\hline Chlorides & $<0.1 \%$ & $>45 \mathrm{minutes}$ \\
\hline Free lime & - & $<10 \mathrm{~mm}$ \\
\hline Physical characteristics & $>75 \mathrm{minutes}$ & $4608 \mathrm{~cm} / \mathrm{g}$ \\
\hline Initial hardening & $<10 \mathrm{~mm}$ & - \\
\hline Expansibility & $4493 \mathrm{~cm}^{2} / \mathrm{g}$ & $>30 \mathrm{MPa}$ \\
\hline Blaine fineness & - & - \\
\hline Compressive strength & - & $>52.5 \mathrm{MPa}$ \\
\hline 2 days & $>16 \mathrm{MPa}$ & \\
\hline 7 days & $>32.5 \mathrm{MPa}$ & \\
\hline 28 days & & \\
\hline
\end{tabular}


Table 2

Types of concrete

\begin{tabular}{|c|c|c|c|c|c|}
\hline \multirow{2}{*}{$\begin{array}{l}\text { Type of } \\
\text { concrete }\end{array}$} & \multirow{2}{*}{$\begin{array}{c}\text { Compressive } \\
\text { strength } \\
f_{c}(\mathrm{MPa})\end{array}$} & \multirow{2}{*}{$\begin{array}{c}\text { Max aggregate } \\
\text { diameter } \\
\Phi_{\max }(\mathrm{mm})\end{array}$} & \multirow{2}{*}{$\begin{array}{l}\text { Particle } \\
\text { size }\end{array}$} & \multicolumn{2}{|c|}{ Nomenclature } \\
\hline & & & & CVC & SCC \\
\hline 1 & 30 & 12 & Fine & V30d12F & S30d12F \\
\hline 2 & 30 & 20 & Coarse & V30d20C & S30d20C \\
\hline 3 & 50 & 12 & Coarse & V50d12C & S50d12C \\
\hline 4 & 50 & 20 & Fine & V50d20F & S50d2OF \\
\hline
\end{tabular}

fly ash, rated as a Portland cement with intermediate strength according to European standards. The composition of these cements is presented in Table [1]. In addition, the following components were employed: limestone filler; rolled, washed natural sand; crushed limestone artificial sand; water reducing multifunctional additive; polycarboxylic-ether-based superplasticizer; and limestone gravel with minimum/maximum diameter of $4 / 7 \mathrm{~mm}, 7 / 12 \mathrm{~mm}$ and 12/20 $\mathrm{mm}$, with the following granulometric modulus: $5.4,6.6$ and 8.5 , respectively. The fineness modulus of the natural sand and artificial sand was 2.8 and 2.5 , respectively.

The concrete was mixed to produce two basic types of concrete: a conventional concrete for general construction and a concrete suitable for prefabricated structures, which were mixed for target compressive strengths of 30 and $50 \mathrm{MPa}$, respectively. Based on these strength values, the variables of interest for this study were chosen, namely, compressive strength, maximum aggregate diameter-12 and $20 \mathrm{~mm}$-and fine and coarse particle sizes.

Given the variables of interest, a statistical analysis based on design of experiments and a method by Taguchi cited in Serna [5] was performed to determine the number of concrete types that are needed to determine the effect of these variables on the mechanical behavior of concrete. This analysis indicated four types of self-compacting concrete (SCC) and four types of conventional vibrated concrete (CVC). The latter four served as a reference. Table [2] lists the types of SCC and CVC according to the variables of interest.

In the nomenclature adopted for the CVC in Table [2], the first letter indicates whether the concrete was vibrated $(V)$ or $(S)$ self-compacting; the number following the first letter indicates the compressive strength class according to the mixing target strength, which may be 30 or $50 \mathrm{MPa}$; the letter $\mathrm{d}$ is the maximum aggregate diameter: $\mathrm{d} 12$ for a maximum diameter of $12 \mathrm{~mm}$ and d20 for a maximum diameter of $20 \mathrm{~mm}$. The last letter indicates the particle size distribution: $F$ denotes fine grain and $C$ denotes coarse grain. After defining the types, the concrete was mixed with the mix proportions of concrete V30d20C and V50d12C employed as the base.

The amount of cement and the water/cement ratio were determined based on the desired compression strength. The proportion of aggregates was obtained from Bolomey's theoretical curve by always adjusting the maximum aggregate diameter and the particle size (Figures [1] and [2]). To obtain a finer or coarser particle size, the

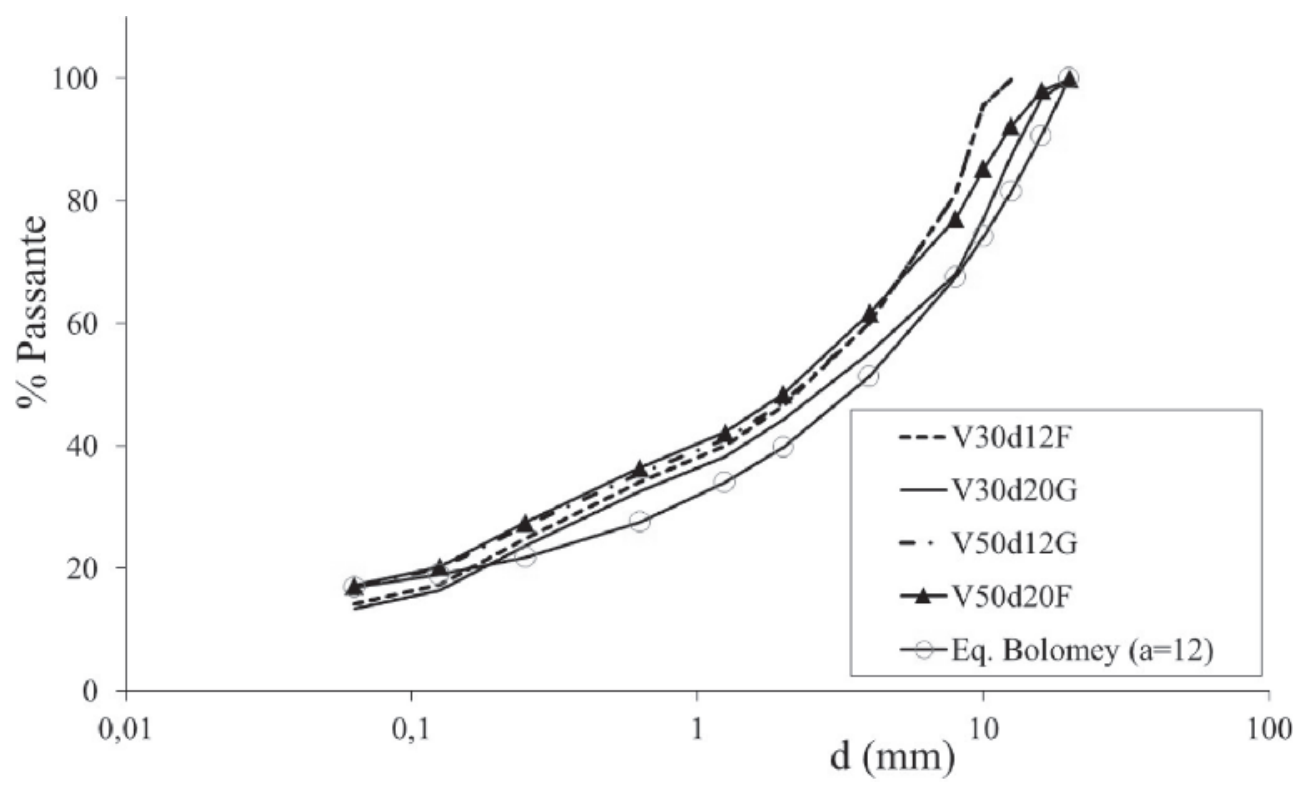

Figure 1

Particle size curve for conventional vibrated concrete 


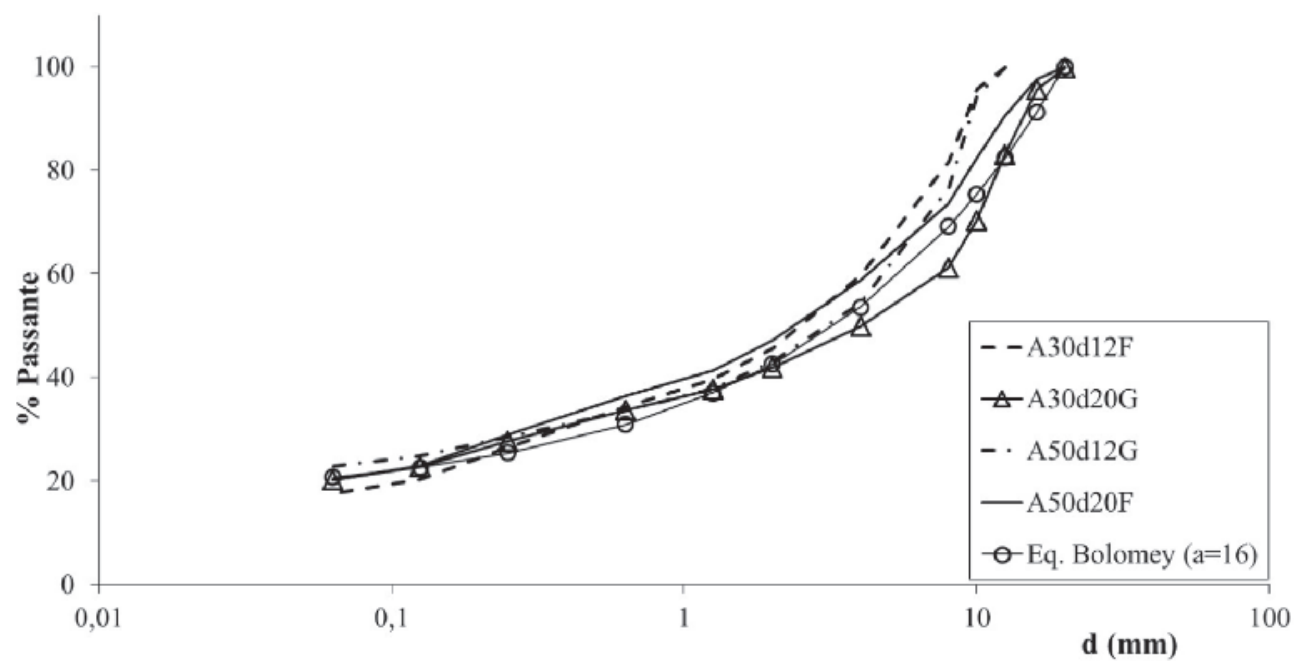

Figure 2

Particle size curve for self-compacting concrete

ratio of crushed stone to sand and the ratio of artificial sand to natural sand were varied. Given the proportion of materials, tests were conducted with the concrete to adjust the amount of plasticizer, superplasticizer additive, and filler material, which was only employed in concrete S30d20C to increase viscosity and prevent segregation of the aggregates. Table [3] lists the composition of the four types of CVC and SCC and the concrete slump test (Abrams cone, S) results for this concrete. The slump height was measured for the CVC, whereas the spreading was measured for the SCC. The occurrence of segregation was verified by visual inspection after the Abrams cone test with the concrete in a fresh state using a longitudinal cut in cylindrical $15 \times 30-\mathrm{cm}$ specimens in a hardened state.

\section{Experimental procedures and methodology}

Following RILEM recommendation TC 89-FMT [5], the SCC postpeak load behavior was characterized based on the fracture en- ergy, according to the maximum load values applied to the specimens and the dimensions of the specimens. Three-point bending tests were conducted with SCC beams, i.e., beams supported at two points with a concentrated load applied in the direction perpendicular to the axis at mid-span, where a notch reduced the crosssectional height and conditioned the locations of the deformations (Figure [3]). Load-crack mouth opening displacement (CMOD) curves were obtained during the tests. Special attention was given to the evaluation of the effect of compressive strength, maximum aggregate diameter and particle size distribution on the properties that characterize the bending behavior of SCC. All experimental stages were performed at the Laboratory of the Institute of Concrete Science and Technology of the Polytechnic University of Valencia (Instituto de Ciencia y Tecnología del Hormigon - ICITECH, Universitat Politècnica de València - UPV) in Spain, according to an agreement between the Graduate Program in Structural Engineering of the Federal University of Minas Gerais (Programa de Pós-Graduação em Engenharia de Estruturas da Universidade

\section{Table 3}

Composition of the materials

\begin{tabular}{|c|c|c|c|c|c|c|c|c|c|c|c|}
\hline \multirow{2}{*}{$\begin{array}{l}\text { Types of } \\
\text { concrete }\end{array}$} & \multirow{2}{*}{$\begin{array}{l}\text { Cement } \\
\left(\mathrm{kg} / \mathrm{m}^{3}\right)\end{array}$} & \multirow{2}{*}{$\begin{array}{l}\text { Water } \\
\left(\mathrm{kg} / \mathrm{m}^{3}\right)\end{array}$} & \multicolumn{3}{|c|}{$\begin{array}{l}\text { Crushed stone } \\
\left(\mathrm{kg} / \mathrm{m}^{3}\right)\end{array}$} & \multicolumn{2}{|c|}{$\begin{array}{l}\text { Sand } \\
\left(\mathrm{kg} / \mathrm{m}^{3}\right)\end{array}$} & \multirow{2}{*}{$\begin{array}{c}\text { Filler } \\
\text { material } \\
\left(\mathrm{kg} / \mathrm{m}^{3}\right)\end{array}$} & \multicolumn{2}{|c|}{$\begin{array}{l}\text { Additives } \\
\left(\mathrm{kg} / \mathrm{m}_{3}\right)\end{array}$} & \multirow{2}{*}{$\begin{array}{l}\text { Abrams } \\
\text { cone } \\
(\mathrm{mm})\end{array}$} \\
\hline & & & $4 / 7$ & $7 / 12$ & $12 / 20$ & Natural & Artificial & & Plast. & Super. & \\
\hline V30d12F & 325 & 195 & 346 & 643 & - & 860 & - & - & 1.89 & - & 100 \\
\hline V30d20C & 325 & 195 & 209 & 366 & 471 & 839 & - & - & 1.80 & - & 120 \\
\hline V50d12C & 380 & 190 & 336 & 623 & - & 834 & - & - & 1.90 & 2.28 & 100 \\
\hline V50d20F & 380 & 190 & 335 & 335 & 287 & 831 & - & - & 2.28 & 1.90 & 140 \\
\hline S30d12F & 325 & 195 & 359 & 538 & - & 750 & 195 & - & 1.63 & 5.20 & 600 \\
\hline S30d20C & 325 & 195 & 142 & 283 & 519 & 533 & 362 & 45 & 2.60 & 5.20 & 600 \\
\hline S50d12C & 380 & 190 & 353 & 432 & - & 524 & 364 & - & 1.90 & 6.08 & 640 \\
\hline S50d2OF & 380 & 190 & 264 & 308 & 308 & 732 & 191 & - & 1.90 & 6.84 & 600 \\
\hline
\end{tabular}



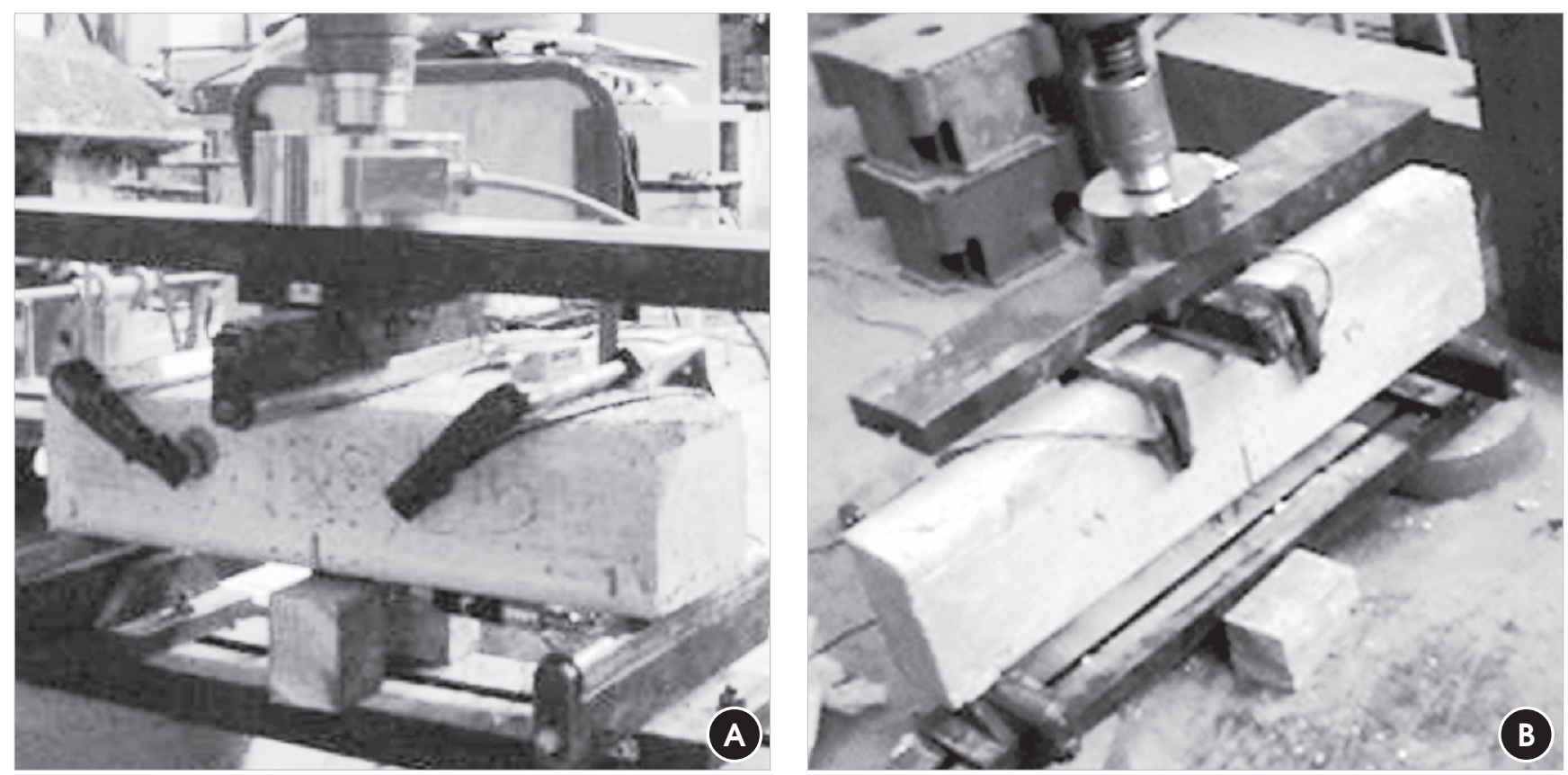

\section{Figure 3}

Three-point bending test in concrete beams with a notch at mid-span and different sizes:

a) beam with the dimensions $80 \times 100 \times 410 \mathrm{~mm}^{3}$; b) beam with the dimensions $160 \times 100 \times 770 \mathrm{~mm}^{3}$

Federal de Minas Gerais - PROPEEs-UFMG) and UPV, supported by the Brazilian Coordination for the Improvement of Higher Education Personnel (Coordenação de Aperfeiçoamento de Pessoal de Nível Superior - CAPES).

Several three-point bending tests were conducted on beams with varying dimensions. The adopted beam dimensions were $80 \times 100 \times 410 \mathrm{~mm}^{3}, 160 \times 100 \times 770 \mathrm{~mm}^{3}$ and $320 \times 100 \times 1500 \mathrm{~mm}^{3}$, with a notch of $1 / 6$ of the height at mid-span. Axial compression tests, diametral compression tests and elastic modulus tests were performed on cylindrical specimens to determine the compressive strength, tensile strength, and modulus of elasticity, respectively. The tests were performed on concrete specimens at 28 days of age. The specimens were kept covered with a plastic sheet in laboratory conditions and were kept in laboratory conditions after unmolding. Notches were made by cutting with a diamond disk 36 to 72 hours prior to testing.

BAŽANT et al. [6] proposed a logical method of applying linear elastic fracture mechanics to concrete to define the fracture energy and size of the fracture process zone in pieces with size tending to infinity, with the parameters $G_{f}$ and $c_{f}$, respectively. These parameters are assumed to be characteristic of the material, independent of size. TC 89-FMT specifies the determination of the fracture energy $\left(G_{f}\right)$ based on the method proposed by BAŽANT et al. [6] using a three-point bending test on concrete beams with a notch at mid-span. In this method, the fracture energy is defined as specific energy, i.e., energy per unit crack plane area, which is required for fracture propagation in infinitely large specimens. Theoretically, the fracture energy is independent of the size and shape of the specimens. The beams should have similar dimensions and different sizes, and the ratio between the height of the section and the span should be kept constant. With fracture energy, the tensile strength must be determined using traditional procedures, such as the diametral compression test on cylindrical specimens and the elastic modulus. With these data, the nominal stress at failure can be determined.

The experimental procedure in this method is simple; the data required to determine the fracture energy consists of the maximum loads values and the dimensions of each tested beam. Sophisticated strain gauge devices are not required. The TC 89-FMT recommendation is based on the applied critical load and the critical effective elastic crack length.

Fracture energy values $\left(G_{f}\right)$ for bodies with infinite dimensions are obtained by extrapolating values for a limited number of specimens with finite dimensions using linear regression. Note that a simple error can significantly change the value of $G_{f}$ when calculating the slope of the regression line.

$G_{f}=\frac{g_{f\left(\alpha_{0}\right)}}{E_{C} A}$

where $E_{c}$ is the modulus of elasticity, $A$ is the slope of the linear regression line, and $g_{f}\left(\alpha_{\partial}\right)$ is the dimensionless fracture energy that is determined from the LEFM, considering the ratio between the span and the height of the beam is 4 , and $\alpha_{0}$ is given by the following relationship: $\alpha_{0}=a_{0} / b$.

The value of $A$ is obtained from the linear regression line $(Y=A X$ $+C)$. The resulting data of the tests are the maximum load and the characteristic dimension of the tested beams, in this case, the height of the section. The weight of each specimen is added to the values of the respective maximum loads. Considering that $Y$ is the 
inverse of the square of the nominal strength of each beam and $X$ is the height of its cross-section, the linear regression of the data formed by the set of paired $X$ and $Y$ values are performed to obtain the equation of the line $(Y=A X+C)$. In the three-point bending test, the values of $X$ and $Y$ are expressed as

$Y=\left(\frac{b \cdot t}{P^{0}}\right)^{2} \quad X=b$

in which $b$ corresponds to the height of the beam, $t$ is the thickness of the beam and $P^{0}$ is the maximum load obtained in the tests added to the weight of the specimen between the supports.

\section{Results and analysis}

The results of the compressive strength, tensile strength and elastic modulus tests are shown in Table [4], as well as the variables of interest for each type of SCC, along with the fracture energy values $\left(G_{f}\right)$ and size of the fracture process zone $\left(c_{f}\right)$. The dispersion of the linear regression was evaluated by the indices $w_{A}, w_{C}$ and $m$, which are also listed in Table [4], in which $w_{A}$ is the dispersion of the linear regression slope, $w_{C}$ is the coefficient of variation that intercepts the regression line and $m$ is the relative width of the dispersion band.

Table [4] reveals that the compressive strengths of concretes V30d12F and S30d12F and concretes V30d20C and S30d20C have similar values. The compressive strengths of concretes $\mathrm{V} 30 \mathrm{~d} 12 \mathrm{~F}$ and $\mathrm{S} 30 \mathrm{~d} 12 \mathrm{~F}$ were $54 \%$ higher than the compressive strengths of $\mathrm{V} 30 \mathrm{~d} 20 \mathrm{C}$ and $\mathrm{S} 30 \mathrm{~d} 20 \mathrm{C}$. This finding is attributed to the finer grain size in $\mathrm{V} 30 \mathrm{~d} 12 \mathrm{~F}$ and $\mathrm{S} 30 \mathrm{~d} 12 \mathrm{~F}$ in relation to the finer grain size in V30d20C and S30d20C. A finer particle size provides better filling of the pores in the interface between the aggregate and the binder, which increases the adhesion between the cement paste and the aggregates.

A suitable correlation between the modulus of elasticity and the compressive strength is shown in Table [4], with a trend toward an increase in the elastic modulus with an increase in the compressive strength in the CVC and the SCC; this relationship is well known in the literature on the subject. In general, the elastic modu- lus values for the $\mathrm{CVC}$ were higher than the elastic modulus values for the SCC due to the smaller amount of coarse aggregates in the SCC and to the lack of minerals with binding properties. The difference between the moduli of elasticity of the CVC and the moduli of elasticity of the SCC was approximately $8 \%$ in the concrete that was mixed for a target compressive strength of $30 \mathrm{MPa}$. This difference decreased to approximately $2 \%$ in the concrete that was mixed for a target compressive strength of $50 \mathrm{MPa}$.

Table [4] reveals that the fracture energy for concrete V30d20C was approximately $12 \%$ higher than the fracture energy for $\mathrm{V} 30 \mathrm{~d} 12 \mathrm{~F}$, whereas the fracture energy for V50d20F was $50 \%$ higher than the fracture energy for V50d12C. For the SCC, S30d12F presented a fracture energy that was $33 \%$ higher than the fracture energy for S30d20C, and S50d12C presented a $G_{f}$ that was $77 \%$ higher than the $G_{f}$ of S50d20F. Additionally, the SCC showed fracture energy values that were lower than the fracture energy values for the corresponding CVC. The only exception was S50d12C, which presented a fracture energy that was equivalent to the fracture energy of V50d12C.

The results listed in Table [4] show that the values for the CVC are slightly above the values suggested by recommendation TC 89FMT, considering the dispersion of the linear regression slope $\left(w_{A}\right)$ and the coefficient of variation that intercepts the regression line $\left(w_{C}\right)$ [5]. The relative dispersion band width $(m)$ was satisfactory. For the SCC, the values of the dispersion coefficients $w_{A}, w_{C}$ and $m$ were lower than the values of the dispersion coefficients suggested by the methodology, with the exception of the coefficients for concrete S50d20F, whose values were higher than the recommended values. This finding may indicate better technological control of the mixing process of SCC in relation to CVC, primarily due to the absence of vibration in the SCC.

The lengths of the FPZ for the SCCs were significantly lower than the values for the corresponding CVC. This result can be explained by the use of a larger amount of fine particles in the SCC. Fines tend to improve the properties of the interface between the aggregate and the binder and generate a greater aggregate grain fracture during crack propagation (Figure [4]). Consequently, the FPZ lengths for the SCC decreased due to lower tortuosity of the crack propagation path.

\section{Table 4}

Composition of the materials

\begin{tabular}{|c|c|c|c|c|c|c|c|c|}
\hline $\begin{array}{l}\text { Type of } \\
\text { concrete }\end{array}$ & $\begin{array}{c}\text { Compressive } \\
\text { strength } \\
\mathrm{f}_{\mathrm{c}}(\mathrm{MPa}) \\
\end{array}$ & $\begin{array}{l}\text { Tensile } \\
\text { strength } \\
f_{f}(\mathrm{MPa}) \\
\end{array}$ & $\begin{array}{l}\text { Modulus of } \\
\text { elasticity } \\
\text { E (MPa) }\end{array}$ & $\mathrm{w}_{\mathrm{A}}$ & $w_{c}$ & $m$ & $\begin{array}{c}G_{f} \\
(N / m)\end{array}$ & $\begin{array}{c}\mathrm{C}_{\mathrm{f}} \\
(\mathrm{mm})\end{array}$ \\
\hline V30d12F & 47.0 & 3.88 & 31644 & 0.76 & 0.36 & 0.42 & 32.36 & 36.21 \\
\hline V30d20C & 29.8 & 4.24 & 27980 & 0.79 & 0.97 & 0.84 & 36.39 & 36.01 \\
\hline V50d12C & 48.3 & 3.25 & 30326 & 0.29 & 0.31 & 0.26 & 22.31 & 15.63 \\
\hline V50d20F & 49.2 & 5.09 & 31574 & 0.77 & 0.36 & 0.39 & 33.65 & 34.68 \\
\hline $\mathrm{S} 30 \mathrm{~d} 12 \mathrm{~F}$ & 45.7 & 4.16 & 29219 & 0.057 & 0.09 & 0.065 & 18.50 & 9.10 \\
\hline S30d2OC & 30.5 & 3.54 & 26104 & 0.17 & 0.13 & 0.13 & 13.90 & 18.18 \\
\hline S50d12C & 52.4 & 4.37 & 29748 & 0.087 & 0.11 & 0.087 & 22.63 & 13.23 \\
\hline S50d20F & 60.2 & 4.85 & 31188 & 0.17 & 0.35 & 0.20 & 12.78 & 8.28 \\
\hline
\end{tabular}



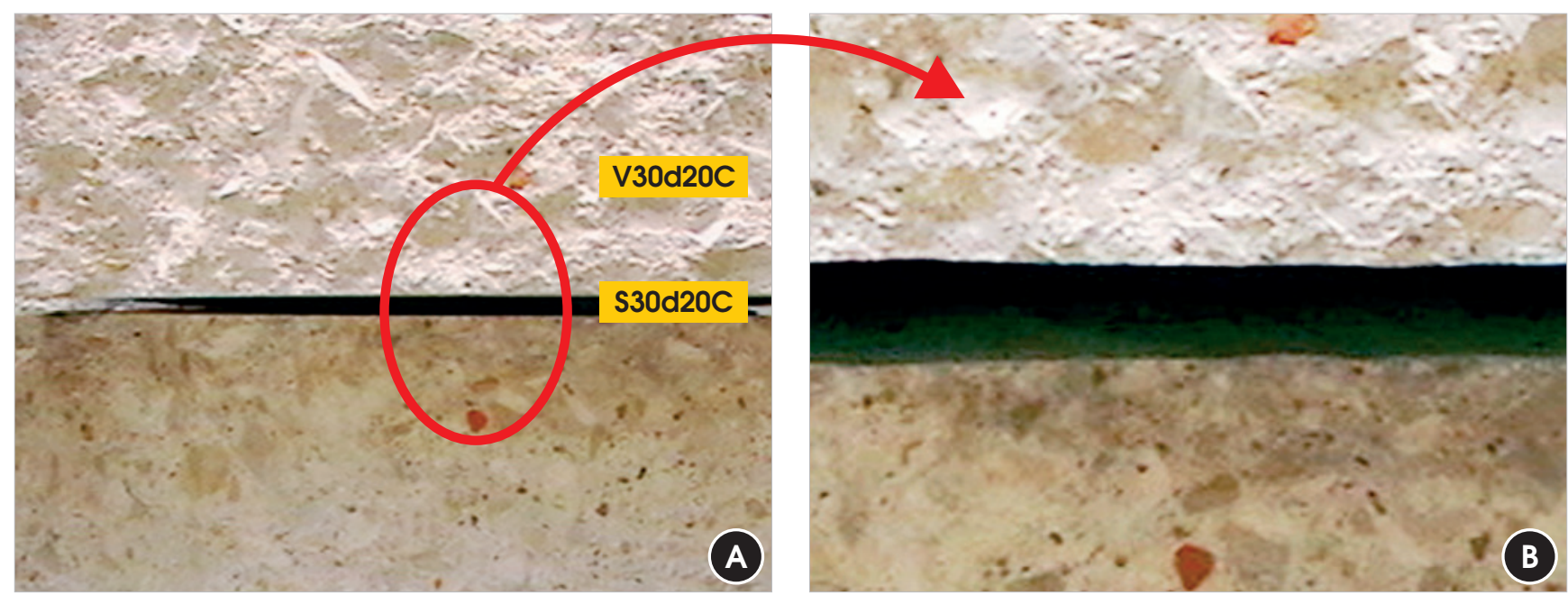

Figure 4

(a) CVC fracture surface (above); SCC fracture surface (below); (b) enlarged detail

Figure [4] shows the fracture surface of a V30d20C beam (upper part of the photo) compared with the fracture surface of an S30d20C beam (lower part of the photo). As shown in Figure [4], V30d20C has a rougher fracture surface that is primarily characterized by crack propagation across the cement paste-aggregate interface, which contours the aggregate surface. In S30d20C, the fracture surface is smoother, in which a high incidence of aggregate grain fractures during crack propagation is observed. Thus, the fracture energy values and the length of the FPZ for SCC were lower than the fracture energy values and the length of the FPZ for the CVC (Table [4]).

The greater aggregate grain fracture in SCC is primarily attributed to the strengthening of the transition zone between the aggregate and the cement paste, considering the larger amount of fines in these concrete. In general, CVC had higher fracture energy values and FPZ lengths than the SCC. Note that the amount of fines can be directly related to the size of the FPZ and that the particle size distribution and the amount of fines in the concrete influences the fracture energy values.

The influence of particle size distribution and maximum aggregate diameter on FPZ length is analyzed by the size effect graph (Figure [5]). The strengths of the concrete structures decrease with an increase in the size of the structures. In general, structures tend to be more brittle as they increase in size, which is described as the size effect and can be explained by fracture mechanics. As shown in Figure [5], note the decline in nominal strength with an increase in the size of the specimen. The decline observed is lower than $-1 / 2$, which corresponds to LEFM. The same figure also shows a band that corresponds to nonlinear fracture mechanics (NLFM). The size effect can be analyzed via the double-logarithmic plot of the logarithm of nominal fracture strength $\sigma_{N}$ divided by the empirical constant $B$ and multiplied by the tensile strength $f_{t}-$ i.e., $\left(\sigma_{\sqrt{N}} / B f_{t}\right)$ - , versus the logarithm of $\beta$, which is the height of the beam divided by the characteristic length. The empirical constant $B$ is calculated
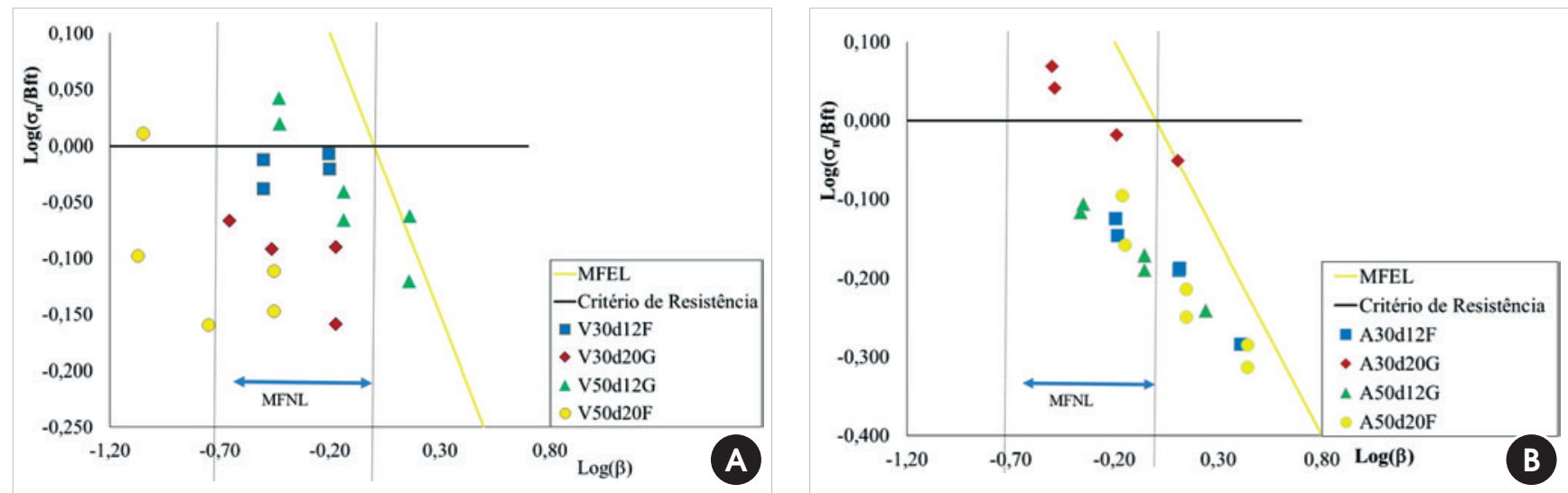

\section{Figure 5}

(a) Size effect for CVC; (b) Size effect for SCCg 
as a function of the value of $C$ of the linear regression line; and $\beta$ is the brittleness index of the material. As shown in Figure [5], the failure stress for the smaller specimens is proportional to the failure stress that is provided by the criteria given by the theory of strength of materials. In this case, a classical strength criterion may be applied to analyze the behaviors of these specimens. The horizontal line in Figure [5] represents a classical strength criterion that is based on stress. Large structures intensely show the size effect, i.e., the strength of the material at failure is proportional to the characteristic dimension of the material and corresponds to the classical LEFM, which is represented by the line with a slope of $-1 / 2$ in relation to the horizontal axis. In the region of the intersection between these two lines, that is, the intersection between the classical strength criterion and the criterion based on LEFM, a transition zone exists where NLFM should be adopted. The results of the majority of the tests performed with the concrete specimens are located in this transition zone (Figure [5]).

Figure [5a] shows that V50d12C is the closest CVC to the LEFM line; it shows the most brittle behavior and the smallest FPZ size, according to the fracture energy and FPZ length results in Table [4]

For the SCC, S50d20F exhibits the most brittle behavior and is significantly closer to the LEFM line (Figure [5b]), according to the $G_{f}$ and $C_{f}$ values in Table [4]. The SCC showed more brittle behavior than the CVC. When S30d12F and V30d12F as well as S50d20F and V50d20F are compared, the addition of fines to the SCC improved the properties of the interface between the aggregate and the paste for this concrete, which rendered them more brittle.

For the SCCs, when comparing S30d12F to S30d20C, note that the increased particle size distribution that is associated with the increased maximum aggregate diameter produced a $25 \%$ reduction in the $G_{f}$ value and an approximately $100 \%$ increase in the $c_{f}$ value. The comparison between S50d12C and S50d20F reveals that the reduced particle size distribution, which is associated with increased maximum diameter, produced a $43.5 \%$ reduction in $G_{f}$ and a $37 \%$ reduction in $c_{f}$ The addition of fine particles to concrete improves the properties of the interface and increases its strength but causes it to become more brittle. A higher incidence of aggregate grain fractures was observed during crack propagation; this observation was noted when comparing the SCCs with the CVCs.

\section{Conclusions}

Based on the tests results, the following inferences were obtained:

- The methodology to determine the fracture parameters of CVC and SCC according to the RILEM TC 89-FMT specification, which is based on the size effect method, was adequate for routine use to characterize the concrete based on fracture mechanics because it is based on a simple load application system that only requires that the maximum load be achieved during the test, without the use of a servo-controlled machine. Thus, this methodology is perfectly viable for the characterization of concrete in a reasonably well-equipped laboratory with respect to aspects of softening and structural brittleness, based on estimates of the following properties: fracture energy and size of the fracture process zone.

- The SCC generally had lower fracture energy values than the fracture energy values of the CVC, as evidenced by the results of the size effect method, according to the RILEM TC 89-FMT recommendation. This brittle behavior is related to the improvement of the interface properties due to the use of a finer particle size distribution in the SCC compared with the CVC.

- The use of artificial sand in the preparation of the SCC to increase the amount of fines was very effective in reducing the cost of production of these two types of concrete.

- The CVC and SCC exhibited similar behavior, considering the compressive strength, which was significantly influenced by the particle size distribution. The use of a finer particle size caused an increase in the compressive strength values. The moduli of elasticity for the SCC were slightly lower than the moduli of elasticity for the reference CVC, considering the same compressive strength level. However, this slight reduction in the modulus of elasticity can be compensated by increasing the productivity of the SCC and improving the construction process, as evidenced by lower coefficient of variation values for the SCC compared to the CVC.

\section{Acknowledgements}

The authors thank the Brazilian Ministry of Education (Ministério da Educação), Coordination for the Improvement of Higher Education Personnel (Coordenação de Aperfeiçoamento de Pessoal de Nível Superior - CAPES), National Council for Scientific and Technological Development (Conselho Nacional de Desenvolvimento Científico e Tecnológico - CNPq), Minas Gerais Research Foundation (Fundação de Amparo à Pesquisa de Minas Gerais - FAPEMIG), and the Ministry of Education and Science of Spain (Ministério de Educación y Ciencia), Project PH2007-0044-PC, Project PCI2006A7-0721 and Program CGCI MECD-DGU Brazil/Spain.

\section{References}

[1] BITTENCOURT, T. N., Fratura do Concreto Estrutural: Aspectos Teóricos Computacionais e suas Aplicações [Fracture of Structural Concrete: Computational Theoretical Aspects and their Applications] Boletim Técnico da Escola Politécnica da Universidade de São Paulo, São Paulo, 1999.

[2] BAŽANT, Z.P.; Size effect in blunt fracture concrete, rock end metal. J. Eng. Mech-ASCE, 110:518-35, 1984

[3] BAŽANT, Z.P.; Concrete fracture models: testing and practice. Engineering Fracture Mechanics. 2002, v.69, 165-205.

[4] BAZANT, Z. P.; PLANAS, J.; Fracture and Size Effect in Concrete and Other Quasi-Brittle Materials, 1998, CRC Press.

[5] Serna, P., Taengua, E.G.; Líneas básicas del diseño y análisis de experimentos. Dpto. de Ing. de la Construcción y Proyectos de Ing. Civil Universitat Politècnica de València.

[6] RILEM - "Draft Recommendation 89-FMC: Size-effect methods for determining fracture energy and process zone size of concrete", Materials and Structure, 1990, v.23, p.461-465.

[7] BAZANT, Z. P.; PFEIFFER, P. A.; Determination of Fracture Energy from Size Effect and Brittleness Number. ACI Materials Journal, 1987, v. 84, pp. 463-480. 